\title{
Instrumento de avaliação para melhorias em processos organizacionais: caso do transporte coletivo rodoviário urbano de Porto Alegre
}

\author{
Miriam Borchardt \\ Miguel Afonso Sellitto \\ Giancarlo Medeiros Pereira \\ UNISINOS
}

\begin{abstract}
Resumo
Este artigo apresenta os dados obtidos a partir de estudos de casos em três empresas de transporte coletivo rodoviário urbano de Porto Alegre, estudos estes realizados no segundo semestre de 2004. 0 objetivo da pesquisa foi desenvolver um instrumento gerencial para a avaliação do potencial de melhoria dos processos destas organizações. Para desenvolver o instrumento de diagnóstico foi considerada a realidade do setor de transporte por ônibus nesta capital e a base teórica referente aos sistemas de gestão baseados na melhoria dos processos, tais como os critérios de excelência do prêmio ANTP de Qualidade, os princípios da Mentalidade Enxuta e do Lean Management. A definição do valor a ser oferecido pelo serviço de transporte, com base na percepção dos usuários, é um ponto que aparece como de grande potencial de melhoria, bem como o equilíbrio entre demanda e capacidade instalada.
\end{abstract}

Palavras-chave

Transporte coletivo urbano, critérios de excelência, melhoria dos processos, produção enxuta.

\section{Assessment instrument for organizational process improvement: the case of urban passengers transportation in Porto Alegre}

\begin{abstract}
This paper presents data and information collected in the second semester of 2004, in a multiple case study developed in three city public bus transportation companies, operating in Porto Alegre. The goal of the research was to develop an instrument for assessing the potential for streamlining processes in companies. To do so, it was considered the business scenario of companies and industry, and the theoretical framework presented in Lean Thinking, Lean Management, Award Excellence Criteria of industry. Issues related to perceived value present the major gaps between the degree of importance and degree of application attributed by these companies. Secondary gaps refer to balancing service capacity and demand.
\end{abstract}

Key words

Public transportation, award excellence criteria, process improvement, lean thinking. 


\section{INTRODUĈ̣̃O}

O aumento do tráfego urbano nas capitais e principais cidades brasileiras tornou o transporte público mais lento e menos confiável. Tal fator, aliado a outros, tais como o transporte clandestino e isenções, reduziu a demanda por viagens remuneradas e a receita do sistema. Uma decorrência do exposto é a necessidade de mais veículos para prestar o mesmo serviço, o que se reflete em aumento de custos. Tal cenário prejudica os usuários cativos do transporte público e desestimula novos usuários. Os usuários cativos, quando possível, optam pelo transporte particular, congestionando ainda mais as vias públicas e realimentando um círculo vicioso (ANTP, 1999).

A Figura 1 ilustra a tendência de queda de passageiros transportados pelo sistema de ônibus urbano nas principais capitais do Brasil. Conforme NTU (2004), o número de passageiros transportados por mês, nas capitais mencionadas na Figura 1, caiu de 406 milhões em 1994 para 267 milhões em 2004 (dados relativos ao transporte regular, não se considerando o transporte clandestino). Observa-se na figura que houve uma modificação de tendência em 2002, que não se sustentou no ano seguinte. Este pico se deveu à adoção de medidas pontuais em algumas capitais, tais como a bilhetagem automática e a transferência não-onerosa entre linhas, mas que logo foram absorvidas pela tendência geral de queda.

Uma vez que a melhoria do transporte coletivo traz benefícios para toda a sociedade e, em especial, para as camadas menos favorecidas, cumpre propor ações que possam melhorar o atual quadro do setor. Desta forma, o presente trabalho analisará as empresas de transporte coletivo rodoviário urbano, identificando alternativas operacionais que possam melhorar os resultados destas organizações frente ao atual cenário de negócios do setor. Uma alternativa a ser considerada pelas empresas é a adoção de princípios e técnicas capazes de diminuir as perdas e, conseqüentemente, aumentar os ganhos das empresas, através de uma maior eficiência do fluxo de valor, estruturado com base nos requisitos do cliente.

A busca pela eliminação das perdas nos processos das organizações leva ao que Henderson e Larco (2002) e Womack e Jones (1998) definiram como sistema enxuto. Um sistema enxuto fornece ferramentas e formas sistêmicas de pensar como eliminar perdas, através da concepção e projeto de produto e processo, da melhoria das atividades e da melhoria das conexões entre processos internos e externos e do fluxo.

Antunes Jr. (1998) destaca que, antes dos sistemas enxutos, a lógica da produção em massa tinha como foco melhorias em operações. Surgiu, então, em oposição, o paradigma centrado em melhorias em processos. Dentre as teorias que legitimam o paradigma, o autor cita: (i) o Sistema Toyota de Produção (STP); (ii) as propostas de qualidade na gestão sugeridas a partir de Deming, Juran, Crosby, Feigenbaum, Ishikawa; (iii) a reengenharia de negócios e de processos; (iv) a Mentalidade Enxuta e (v) o Lean Management.

O objetivo deste trabalho é apresentar um instrumento gerencial para a avaliação do potencial de melhoria dos

Figura 1: Passageiros transportados por mês.

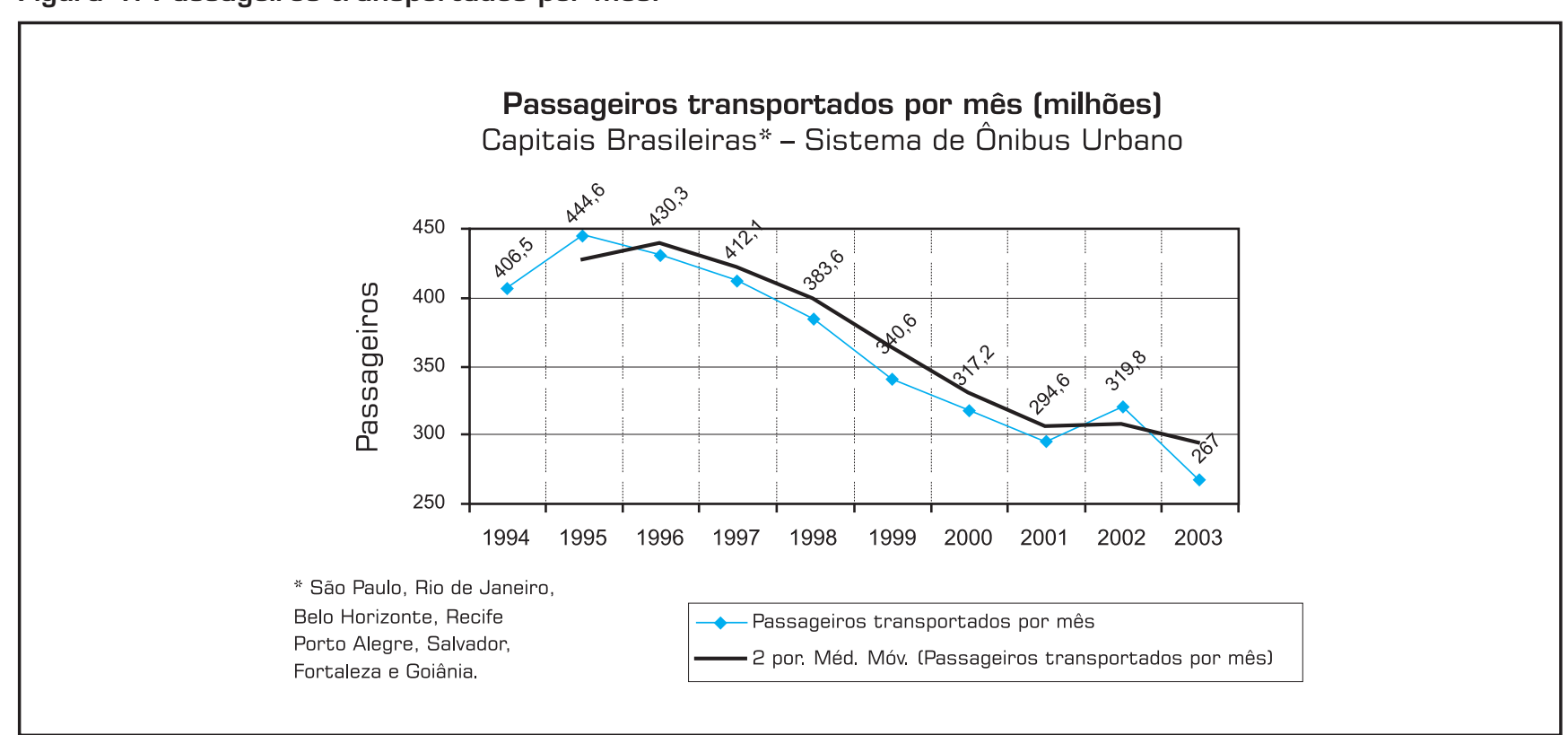

Fonte: NTU (2004) 
processos de organizações de transporte coletivo rodoviário urbano. $\mathrm{O}$ instrumento foi construído a partir de uma base teórica estruturada, que se originou dos sistemas enxutos e da melhoria contínua. Com a aplicação do instrumento, será possível, para as empresas, escolherem técnicas e ferramentas apropriadas para a sua realidade e priorizarem as ações de maior ou mais urgente potencial de melhorias. A questão de pesquisa que surge é: como as empresas de transporte coletivo rodoviário urbano podem identificar os principais processos a serem melhorados, de modo a reduzir perdas e, conseqüentemente, aumentar ganhos?

\section{I sistema enxuto fornece ferramentas e formas sistêmicas de pensar como eliminar perdas.}

Embora a abordagem dos sistemas enxutos e o conceito de melhoria contínua não sejam as únicas formas de melhoria de processos, é uma delimitação de pesquisa ater-se às mesmas. Este trabalho é parte de um projeto de pesquisa de quatro anos, conduzido pelo então grupo de pesquisa da engenharia de produção da UNISINOS, agora grupo de pesquisa do PPGEPS UNISINOS, realizado entre 2002 e 2005. A principal motivação do projeto foi o estudo das possibilidades da aplicação da Mentalidade Enxuta, como campo de conhecimento, de gerar um modelo de apoio à gestão da indústria de transporte coletivo, tal como o gerou o campo da qualidade total. As principais publicações decorrentes dos resultados do projeto são: Sellitto, Borchardt e Pereira (2003) e Sellitto, Borchardt e Pereira (2006). Duas teses recentes de doutoramento utilizaram achados de pesquisa: Borchardt (2005) e Sellitto (2005). Outros campos de conhecimento, tais como a teoria das restrições e a análise de valor, mesmo que com potencial para o objetivo do projeto, estão fora de seu escopo.

O restante do artigo está organizado em: apresentação das características do transporte coletivo rodoviário urbano em Porto Alegre; referencial teórico de sustentação do instrumento de avaliação; delineamento da pesquisa e estrutura do instrumento; três casos de aplicação; e considerações finais.

\section{CARACTERÍSTICAS DO TRANSPORTE COLETIVO DE PORTO ALEGRE}

Costa et al. (2001) descrevem que, em Porto Alegre, o transporte coletivo por ônibus é regulamentado desde 1928, quando vigorou o primeiro ato determinando as linhas e os horários dos ônibus e bondes da cidade. A partir de então, o sistema funcionou com permissão por linha e por empresa.
Há, em Porto Alegre, quinze empresas de transporte coletivo por ônibus, sendo uma pública e quatorze privadas. Em 1992, o transporte por ônibus foi organizado em grupos de empresas, os consórcios. O consórcio Conorte é formado por três empresas que, juntas, totalizam 416 veículos e atendem a bacia geográfica norte. O consórcio Unibus tem 370 veículos e seis empresas, que atendem a bacia geográfica leste. O consórcio STS é formado por cinco empresas que atuam na bacia geográfica sul e totalizam 447 veículos. As linhas transversais são atendidas pela empresa pública, a Carris, com 323 veículos (EPTC, 2004).

O equilíbrio econômico-financeiro do sistema foi preservado pela adoção de mecanismo de compensação financeira, mediante o qual as empresas superavitárias, por possuírem linhas com custos internos inferiores à média, repassam parte da receita às empresas operando em situação deficitária. A Câmara de Compensação Tarifária (CCT) é responsável pelos repasses entre as bacias geográficas, incluindo a Carris. Os consórcios, por sua vez, administram a compensação interna entre as empresas, com base no percentual de custos de cada uma (AZAMBUJA, 2002).

Segundo o STS (2004), os consórcios apresentam como vantagens: (i) ordenamento dos horários de todas as linhas de uma dada bacia geográfica da cidade; (ii) possibilidade da criação de linhas rápidas, diretas e semidiretas; (iii) diminuição dos tempos de viagens; (iv) maior flexibilidade para suprir horários com maior demanda; e (v) melhor qualidade na prestação do serviço.

O sistema de transporte coletivo em Porto Alegre é regulamentado por um órgão gestor, a Empresa Pública de Transporte e Circulação - EPTC. O órgão estabelece os critérios de produção, por tabelas horárias, que especificam horários, cargas, itinerários e requisitos de qualidade do serviço. Os requisitos são aferidos periodicamente junto aos usuários por pesquisas de informação, nas quais se detectam qualitativamente que requisitos são relevantes para a satisfação dos usuários e, quantitativamente, em que graus são satisfeitos. Cabe às empresas o gerenciamento para que se atinjam estes requisitos e se cumpram os objetivos de produção. Dados destas pesquisas, tomados como dimensões de desempenho, são explorados por Sellitto e Borchardt (2004) em uma análise multivariada que pode ser considerada em formulações de estratégia de prestação de serviço no setor.

A EPTC (2004) destaca que o transporte clandestino ou irregular praticamente inexiste em Porto Alegre e não está regulamentada a atividade de mototáxi. A empresa considera que ações estruturais tomadas até o fim da década de 1980, tais como os corredores exclusivos de alta velocidade para ônibus e os serviços regulamentados e fiscalizados de lotação e de transporte escolar, não permitiram o surgimento de práticas clandestinas. A queda 
no número de passageiros transportados pelo sistema foi de $13,89 \%$ entre 1998 e 2003 e deve-se, sempre segundo a empresa, apenas a fatores estruturais ligados à conjuntura social brasileira, e não a fatores circunstanciais, tais como os clandestinos.

\section{REFERENCIAL TEÓRICO}

Diversas opções teóricas, técnicas e ferramentas, casos e aplicações, cujos princípios convergem para a idéia central de eliminação de perdas e melhoria em processos, são disponíveis na literatura, tais como em: Ballard (2003); Cerra e Bonadio (2000); Cunningham, Young e Lee (2000); Cypriani e Guedes (2002); Fullerton, McWatters e Fawson (2003); Henderson e Larco (2002); Johnston et al. (2001); Nilsson, Johnson e Gustafsson (2003); Sánchez e Pérez (2001); Kaynak (2003).

\section{Critérios de Excelência do Prêmio ANTP de Qualidade}

Os critérios de excelência da Fundação Nacional para Qualidade (FNQ) e os critérios de excelência do BNQP(Baldrige National Quality Program) são a base para o Prêmio ANTP de Qualidade. Sendo o Prêmio ANTP de Qualidade a referência para o setor de transportes públicos, descreve-se a estrutura do mesmo e suas características.

O Prêmio ANTP de Qualidade foi criado em 1995 por decisão da Comissão de Qualidade e Produtividade da ANTP (Associação Nacional dos Transportadores de Passageiros) com o objetivo de estimular as organizações de transporte e trânsito a adotarem modelos de gestão orientados para a excelência de desempenho de cada um dos seus processos e, em conseqüência, melhorarem a qualidade de seus serviços de forma contínua e sustentada.

O Prêmio ANTP de Qualidade 2005 está estruturado em sete critérios (ANTP, 2004).

1) Liderança: examina como a alta direção estabelece e dissemina os valores organizacionais, as diretrizes e as expectativas de desempenho, bem como o foco nos clientes e demais partes interessadas.

2) Planejamento Estratégico: examina como a organização define suas estratégias e as desdobra em planos de ação.

3) Foco nos Clientes e na Sociedade: examina como a organização identifica e se antecipa aos requisitos, expectativas e preferências de seus clientes e da sociedade.

4) Mensuração, Análise e Gestão do Conhecimento: examina como a organização seleciona, obtém, analisa e melhora seus dados, informações e conhecimentos.

5) Gestão de Pessoas: examina como são proporcionadas condições para o desenvolvimento e utilização plena do potencial das pessoas que compõem a força de trabalho.

6) Gestão de Processos: examina os principais aspectos da gestão dos processos da organização, incluindo o projeto dos serviços/produtos com foco no cliente, a produção dos serviços, os processos de apoio e aqueles relacionados aos fornecedores.

7) Resultados da Organização: examina a evolução do desempenho da organização em relação aos clientes, aos serviços e produtos, à situação financeira, ao mercado, às pessoas, aos fornecedores, aos processos e à sociedade.

O Prêmio ANTP de Qualidade pode servir de base para uma auto-avaliação das organizações, a partir de dimensões e parâmetros preestabelecidos. Desta forma, as organizações podem visualizar os pontos fortes e os pontos de melhoria e priorizar ações.

\section{Mentalidade Enxuta}

A Mentalidade Enxuta é uma forma de tornar o trabalho mais satisfatório, oferecendo realimentação imediata sobre os esforços para transformar desperdícios em valor. Conforme Womack e Jones (1998), os cinco princípios gerais da Mentalidade Enxuta são:

1) determinar precisamente o valor por produto específico: Hines e Taylor (2000) e Schonberger (1990) salientam que o valor necessariamente deve ser determinado sob a perspectiva do cliente;

2) identificar a cadeia de valor: segundo Porter (1999), a reunião das atividades que são executadas para projetar, produzir, comercializar, entregar e sustentar seu produto compõe a cadeia de valor de uma empresa;

3) fazer o valor fluir sem interrupções: Rother e Shook (1999) definem fluxo de valor como toda ação (agregando valor ou não) necessária para trazer um produto por todos os fluxos essenciais para sua produção;

4) adotar sistema de produção puxada: um processo inicial apenas deve produzir um bem ou serviço a partir da solicitação do processo posterior; em organizações de serviços, Davis (2001) ressalta a importância de sincronizar a demanda e a capacidade; e,

5) buscar a perfeição: pode ocorrer por melhorias contínuas incrementais, o kaizen, e por melhorias radicais, o kaikaku.

\section{Lean Management}

O Lean Management, segundo Jackson e Jones (1996), busca alinhar as estratégias da organização, e por meio de uma estrutura apropriada e do fortalecimento das forças competitivas, garantir a melhoria dos processos. Para tanto, os autores estabeleceram nove diretrizes, denominadas de áreas chaves, a serem estruturadas e desenvolvidas na busca de um sistema enxuto. As mesmas são descritas na seqüência.

1) Foco no cliente: alinha-se com a idéia de um nível zero de insatisfação dos clientes. 
2) Liderança e estratégia: é a capacidade do time gerencial de traduzir os requerimentos dos clientes em uma política concreta e objetiva, com metas claras e comunicáveis.

3) Organização enxuta: refere-se à estrutura de interação entre times e áreas, que deve ser estabelecida para minimizar redundâncias e capacidade administrativa requerida pelas operações.

4) Parcerias: é o conjunto de relacionamentos e alianças de longo prazo, baseado na confiança e que envolve empregados, fornecedores e sociedade.

5) Arquitetura da informação: refere-se à estrutura de criação e distribuição de informações que dê suporte à estrutura organizacional.

6) Cultura de melhoria: diz respeito à capacidade de times e indivíduos analisarem as defasagens em relação à estratégia e problemas de qualidade para encontrar as causas raízes e conceber, implementar e padronizar as soluções efetivas.

7) Produção enxuta: inclui a utilização de técnicas para a redução de perdas.

8) Manutenção enxuta: refere-se à abordagem da Manutenção Produtiva Total (TPM) que garante eficiência, precisão e facilidade na operação e manutenção, além de disponibilidade de máquinas, equipamentos e sistemas.

9) Engenharia enxuta: refere-se à prática da engenharia simultânea ou outros métodos para o desenvolvimento de novos produtos de forma rápida e consistente.

\section{A PESQUISA}

Seguem a organização dada ao referencial teórico, o delineamento de pesquisa, a aplicação e os resultados auferidos com a mesma.

\section{Considerações sobre o referencial teórico}

Ao analisar criticamente as três abordagens do referencial teórico, procura-se identificar elementos que atendam os objetivos de pesquisa. Caso se entenda que não seja função de teorias ou filosofias fundamentais a prescrição de práticas operacionais, algumas lacunas surgem e podem ser preenchidas por pesquisa específicas.

O modelo de gestão baseado no Prêmio ANTP de Qualidade 2005 não vincula ferramentas ou práticas de gestão aos critérios do referido Prêmio, podendo-se escolher as mais convenientes para o caso. A Mentalidade Enxuta não prescreve como questões estratégicas e de vantagem competitiva devem ser consideradas na definição de valor ou como medir desempenho. Sellitto, Borchardt e Pereira (2006) propuseram uma estrutura de mensuração de desempenho em Mentalidade Enxuta que foi aplicada em transporte urbano de passageiros. O Lean Management introduz elementos capazes de sustentar a implementação de sistemas enxutos, por meio da estratégia, da estrutura e das forças competitivas, mas, como esperado, não menciona aspectos relativos aos resultados nem sugere ferramentas e técnicas para implementação.

Sintetizam-se no Quadro 1 os elementos das abordagens estudadas, que serão examinados. O objetivo do quadro não é emparelhar pontos de interesse abordados nas diferentes teorias, mas identificar onde e como estes surgem nas mesmas.

Estratégia, mensuração e análise das informações e pessoas são referenciadas tanto no Lean Management como no Prêmio ANTP

A implementação de um sistema enxuto necessita, segundo Jackson e Jones (1996), ser sustentada por elementos constitutivos baseados em gerenciamento interfuncional, trabalho em equipe, desenvolvimento organizacional e estratégias de curto e longo prazo. Henderson e Larco (2002) reforçam essa necessidade, salientando a importância dos gestores conhecerem ferramentas apropriadas a cada situação e a cada estágio de desenvolvimento da implementação do sistema enxuto.

Apresentados os pilares teóricos, o próximo tópico tece considerações acerca dos elementos de cada abordagem, apropriados para esta investigação. Os mesmos formam a base de estruturação do instrumento gerencial de avaliação do potencial de melhoria dos processos das organizações de transporte coletivo rodoviário urbano. de Qualidade. Valor consta nas três abordagens, sendo que no Lean Management e no Prêmio ANTP apresenta-se como "foco no cliente". Fluxo de valor, citado nas três abordagens, consta no Lean Management como sendo "produção enxuta" e "organização enxuta". Sistema de valor, também nas três abordagens, pode ser associado no caso em estudo a "parceiros e fornecedores" no Lean Management e como "processos relativos aos fornecedores" no Prêmio ANTP. Produto/serviço está inserido no item "gestão de processosprojeto do produto" e refere-se à capacidade de a organização definir produtos/serviços em função do valor definido pelo cliente. Produção puxada, no contexto deste trabalho, refere-se à capacidade da organização de serviço projetar e operar um fluxo de serviço síncrono à demanda; no caso em estudo, pode ser associada à "engenharia enxuta" do Lean 
Quadro 1: Parâmetros do Prêmio ANTP de Qualidade 2005, da Mentalidade Enxuta e do Lean Management.

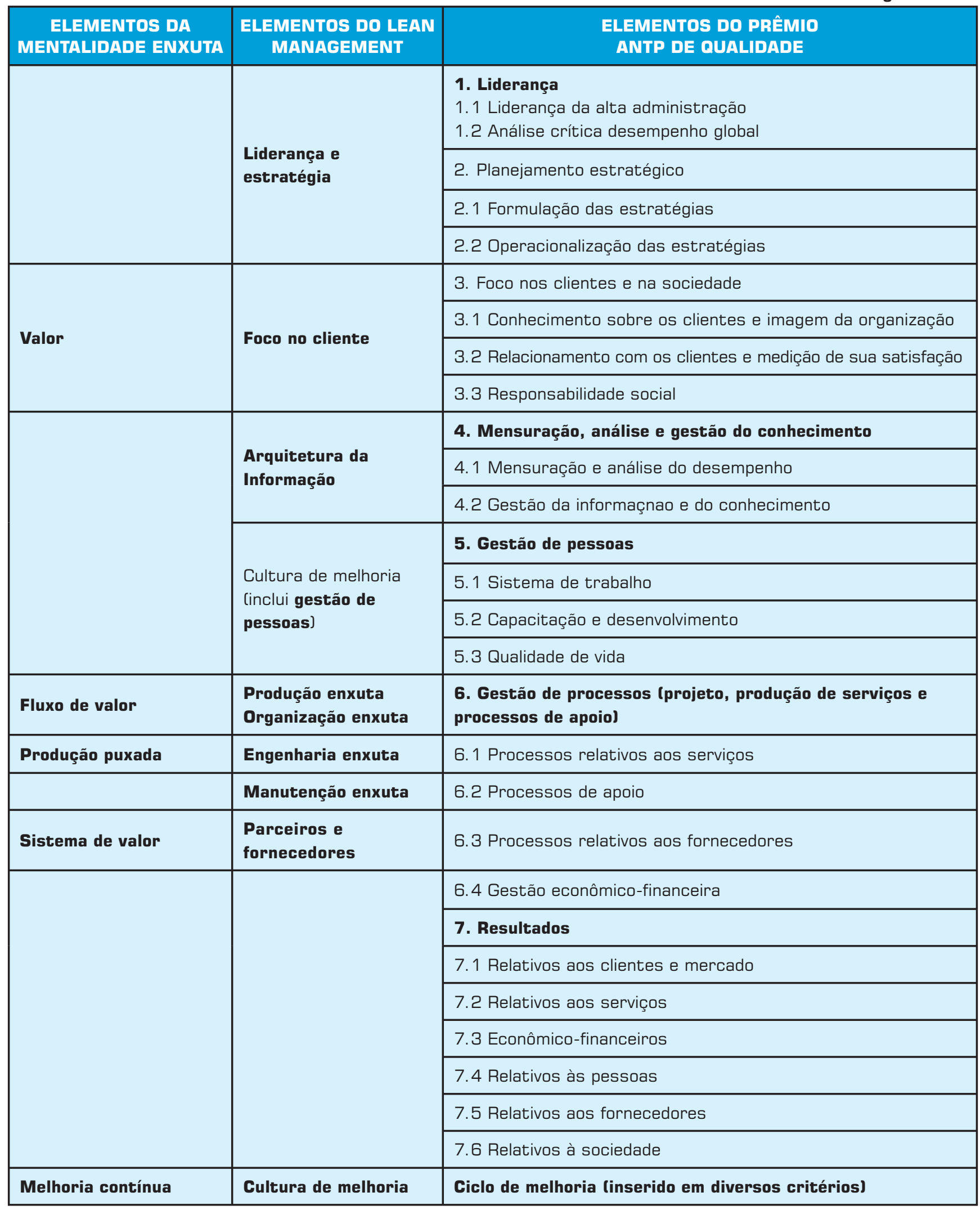


Management e aos "processos relativos aos serviços" do Prêmio ANTP. A produção puxada no caso em estudo pode ser obtida por aproximações temporais, por rotas mais freqüentes; e espaciais, por capilaridades distintas em horários e locais mais demandados. Outra alternativa combina as duas aproximações: veículos pequenos nos horários e capilaridades menores; veículos grandes nos maiores; veículos intermediários em combinações intermediárias. Ações de melhoria é citada nas três abordagens. Por fim, Resultados é mencionado no Prêmio ANTP sendo uma conseqüência da implementação bem-sucedida da estratégia.

anterior, publicada em Sellitto, Borchardt e Pereira (2003). Nesta pesquisa, as quinze empresas de transporte coletivo de Porto Alegre foram classificadas em três grupos, conforme sua capacidade de compreensão dos princípios da Mentalidade Enxuta e conceitos correlacionados, como os relativos ao Sistema da Qualidade, a Gestão de Processos e a Estratégia. Os grupos foram: (i) empresas cujos gestores conhecem os conceitos relativos aos sistemas enxuto e da qualidade; (ii) empresas cujos gestores conhecem parcialmente os conceitos relativos aos sistemas enxuto e da qualidade; e (iii) empresas cujos gestores não conhecem tais conceitos. Optou-se por trabalhar com as seis empresas do primeiro grupo, para minimizar erros de interpretação e compreensão de conceitos utilizados no instrumento de diagnóstico.

Três empresas, dentre as seis do primeiro grupo, aceitaram participar da pesquisa. As mesmas foram denominadas de "A", "B" e "C" e pertencem a consórcios diferentes. A empresa "A" possui cerca de 200 veículos.

Os elementos do Quadro 1 serão usados como base teórica para a composição do instrumento gerencial de avaliação, devido à sua adequação aos propósitos da investigação. Neste trabalho, esses elementos serão denominados de bases de análise: Estratégia, Valor, Sistema de valor, Produto/serviço, Fluxo de valor, Produção puxada, Pessoas, Mensuração e análise das informações, Resultados e Ações de melhoria.

A seguir, delineia-se a investigação.

\section{Delineamento da investigação}

A pesquisa envolve a obtenção de dados descritivos de modo a compreender os fenômenos segundo a perspectiva dos participantes da situação em estudo, para, então, sustentado por teorias e princípios convergentes com a busca da melhoria dos processos, identificar as lacunas nas práticas das organizações e os parâmetros considerados relevantes pelas mesmas.

A pesquisa é exploratória e a estratégia escolhida é o estudo de caso. Segundo Yin (2001), esta técnica é indicada quando se examinam acontecimentos contemporâneos e não se pode manipular ou influenciar comportamentos relevantes. Além disso, objetiva-se compreender "como" as empresas se posicionam em relação à implementação dos elementos avaliados. Para a compreensão de "como" um determinado fenômeno ocorre, Voss, Tsikriktsis e Frohlich (2002) sugerem o estudo de caso como técnica de pesquisa. Outro ponto que sustenta a aplicação da técnica do estudo de caso é o fato de a pesquisa caracterizar-se por um relacionamento próximo entre pesquisador e organizações estudadas e pela coleta de dados segundo instrumento predefinido (roteiro para entrevista).

A unidade de análise é composta por três empresas de Porto Alegre, selecionadas em uma pesquisa exploratória
A empresa "B", com 90 veículos, possui certificação ISO 9001:2000 e em 2004 recebeu o troféu Ouro do PGQP (Programa Gaúcho de Qualidade e Produtividade). A empresa "C", com cerca de 300 veículos, também possui certificação ISO 9001:2000.

O método de trabalho constou das seguintes fases: (i) desenvolvimento do referencial teórico já apresentado, relacionada aos Critérios de Excelência do Prêmio ANTP de Qualidade, aos princípios da Mentalidade Enxuta, aos fundamentos do Lean Management e uma análise das características e estrutura do transporte coletivo rodoviário urbano de Porto Alegre; (ii) o desenvolvimento do instrumento de diagnóstico, avaliado por três especialistas das áreas de transporte e sistemas enxutos e submetido a teste piloto, antes de assumir sua forma final; (iii) aplicação do instrumento de diagnóstico às empresas; e (iv) consolidação das informações coletadas e análise dos resultados. As empresas indicaram os especialistas respondentes. Preparou-se um roteiro para a entrevista, que incluiu a aplicação do instrumento de diagnóstico e visitas para observação direta.

A pesquisa limita-se a investigar aspectos relativos às empresas de transporte e não estende os resultados às outras organizações que formam a cadeia de valor do sistema de transporte coletivo por ônibus, tais como o órgão gestor, os consórcios, os fornecedores de carrocerias, chassis, motores, peças de reposição e insumos. Este estudo não permite generalizações para as demais empresas da indústria, haja vista que relata a situação de organizações com alto grau de aplicação e compreensão dos itens avaliados; destaca-se que esta não é a realidade de todas as empresas da indústria, conforme Sellitto, Borchardt e Pereira (2003). 


\section{Elaboração do instrumento de diagnóstico}

$\mathrm{O}$ instrumento de diagnóstico propõe-se a identificar os elementos que, segundo a percepção das empresas, são os mais relevantes para a melhoria dos processos e em que grau os mesmos estão sendo utilizados. Também guiou as entrevistas e a coleta de outras informações, fornecidas pelos entrevistados.

Para facilitar a organização dos dados, cada base de análise foi desdobrada em pontos-chave, que foram desdobrados em pontos de análise. Associaram-se aos mesmos questões que mensuram o grau de importância e de aplicação de cada parâmetro e conduzem a entrevista para a busca de informações mais detalhadas sobre "o que" e "como" a empresa procede em diversas situações. Os parâmetros avaliados em cada base de análise surgem no Quadro 2.

A cada questão foram associadas duas escalas de Likert, com valores de 1 a 5 . A primeira escala corresponde ao grau de importância que a organização atribui para cada questão do ponto de análise e a segunda corresponde ao atual estágio de implementação de cada item. A relação entre os atributos qualitativos e os valores numéricos da escala de Likert foi adaptada da Tabela de Critérios do Prêmio ANTP de Qualidade 2005 (ANTP, 2004) e é apresentada no Quadro 3. Para cada questão, serão anotadas as justificativas dos respondentes para o valor atribuído, o que é um ponto rico da pesquisa em termos de coleta de informações.

O próximo tópico descreve os resultados da aplicação do instrumento de diagnóstico.

\section{Aplicação e resultados}

Apresentam-se informações apuradas junto aos entrevistados sobre "o que" e "como" a empresa procede nas situações investigadas. A síntese dos valores numéricos atribuídos a cada questão será apresentada no próximo tópico, pois a abordagem quantitativa complementa os aspectos qualitativos levantados.

Para a base de análise "Estratégia", as questões relativas à formulação de estratégia e à liderança são consideradas muito importantes ou extremamente importantes pelos entrevistados das três organizações. Quanto à proposição de valor, para duas organizações, o aspecto é considerado extremamente importante; para uma das empresas, este parâmetro tem importância média, pois, por restrições de legislação, há pouca flexibilidade e possibilidade de as empresas inovarem e gerarem novos produtos.

Na base de análise "Valor", duas empresas consideram muito importante ou extremamente importante conhecer as características gerais dos clientes, a finalidade com que usam o transporte e os fatores de decisão que levam os mesmos a optar pelo ônibus. Uma empresa avalia esses parâmetros como importância média, pois opera com linhas de público de baixa renda, sem opções de transporte. Mesmo assim, essa organização é a que mais ênfase dá à realização de pesquisas próprias, buscando identificar seu cliente e requisitos, o que denota atenção ao parâmetro.

Nas questões relativas ao mercado atual, as empresas assinalaram que é extremamente importante mapeá-lo e conhecer suas reais dimensões e as ameaças de concorrentes de outros modais. Com relação ao mercado potencial, as empresas consideram o mesmo cada vez mais escasso.

Com respeito às respostas referentes à base de análise "Sistema de valor", não há integração entre as empresas dos consórcios, visando otimizar o uso de recursos. A comunicação entre o órgão gestor e as empresas, segundo os entrevistados, perde parte da eficiência, pois é feita através do consórcio. A velocidade de atuação é baixa e o foco está voltado para o cumprimento de horários. Os consórcios têm uma atuação mais ampla no que se refere à operação do sistema de transporte.

\section{Lean Management busca alinhar} as estratégias da organização e, por meio de uma estrutura apropriada, garantir a melhoria dos processos.

Na base de análise "Produto/serviço", as empresas "B" e "C" consideram relevante desenvolver novos serviços e atuam ativamente para propor novas linhas junto ao órgão gestor, acompanhar sua implantação e efetuar ajustes no nível de serviço oferecido. Segundo os entrevistados, os parâmetros relacionados ao serviço, na percepção do cliente, são mais relevantes do que os relativos aos equipamentos (ônibus). As dificuldades de atendimento aos requisitos desta base de análise estão relacionadas à interação da cadeia de valor e as formas de garantir e medir a fidelidade dos clientes.

Na base de análise "Fluxo de valor", com relação aos processos de apoio e aos processos em geral, as três organizações consideram muito importante ou extremamente importante terem as rotinas de trabalho e procedimentos definidos e difundidos, bem como identificar, tipificar, eliminar, quantificar e mudar os processos. Na empresa "A", segundo o entrevistado, nem sempre a qualidade tem sido vista como responsabilidade dos próprios executores.

A efetiva implementação de rotinas para melhoria dos processos mostrou-se, nas três organizações, aquém da importância atribuída. A empresa "A" considera que não trabalha de forma sistêmica e que não tem focado a eliminação das perdas. A empresa "C" também não vinha priorizando a eliminação das perdas. A empresa "B" atua 
Quadro 2: Parâmetros de avaliação em cada base de análise

\begin{tabular}{|c|c|c|c|}
\hline $\begin{array}{l}\text { BASES DE } \\
\text { ANÁLISE }\end{array}$ & PONTOS-CHAVE & PONTOS DE ANÁLISE & PARAMMETROS A AVALIAR \\
\hline \multirow{6}{*}{ Estratégia } & \multirow{3}{*}{$\begin{array}{l}\text { 1. Formulação da } \\
\text { estratégia }\end{array}$} & 1.1. Desdobrar planos de ação & \multirow{6}{*}{$\begin{array}{l}\text { Capacidade de gerar os resultados } \\
\text { esperados. }\end{array}$} \\
\hline & & 1.2. Balancear as necessidades & \\
\hline & & 1.3. Comunicar as estratégias & \\
\hline & \multirow{2}{*}{ 2. Liderança } & 2.1. Disseminar valores da empresa & \\
\hline & & 2.2. Analisar desempenho global & \\
\hline & 3. Proposição valor & 3.1. Proposição de valor da empresa & \\
\hline \multirow{4}{*}{ Valor } & \multirow{2}{*}{ 4. Cliente } & 4.1. Características dos clientes & \multirow{4}{*}{$\begin{array}{l}\text { Capacidade de conhecer } \\
\text { características dos clientes e como } \\
\text { estes percebem o valor do serviço } \\
\text { oferecido. }\end{array}$} \\
\hline & & 4.2. Percepção de valor pelo cliente & \\
\hline & \multirow{2}{*}{ 5. Mercado } & 5.1. Mercado atual & \\
\hline & & 5.2. Mercado potencial & \\
\hline \multirow{4}{*}{$\begin{array}{l}\text { Sistema de } \\
\text { valor }\end{array}$} & $\begin{array}{l}\text { 6. Cadeia de valor } \\
\text { (interna) }\end{array}$ & $\begin{array}{l}\text { 6.1. Conhecimento do cliente } \\
\text { interno }\end{array}$ & \multirow{4}{*}{$\begin{array}{l}\text { Capacidade de integrar a cadeia de } \\
\text { valor e demais parceiros na busca de } \\
\text { objetivos comuns baseados no valor } \\
\text { definido pelo cliente. }\end{array}$} \\
\hline & \multirow{3}{*}{ 7. Parceiros } & 7.1. Fornecedores & \\
\hline & & 7.2. Consórcio & \\
\hline & & 7.3. Órgão gestor & \\
\hline \multirow{3}{*}{$\begin{array}{l}\text { Produto / } \\
\text { serviço }\end{array}$} & \multirow{2}{*}{$\begin{array}{l}\text { 8. Projeto do } \\
\text { produto }\end{array}$} & $\begin{array}{l}\text { 8.1. Projeto de equipamentos } \\
\text { [ônibus] }\end{array}$ & \multirow{3}{*}{$\begin{array}{l}\text { Capacidade de garantir que os } \\
\text { produtos e serviços foram concebidos } \\
\text { com base no valor percebido pelo } \\
\text { cliente e que as operações são } \\
\text { executadas para garantir os } \\
\text { resultados esperados. }\end{array}$} \\
\hline & & 8.2. Projeto do serviço & \\
\hline & 9. Serviço & 9.1. Serviço & \\
\hline \multirow{6}{*}{$\begin{array}{l}\text { Fluxo de } \\
\text { valor }\end{array}$} & \multirow{2}{*}{$\begin{array}{l}\text { 10. Processo em } \\
\text { geral }\end{array}$} & 10.1. Organização dos processos & \multirow{6}{*}{$\begin{array}{l}\text { Capacidade de garantir que o valor flua } \\
\text { ao longo de todas as etapas da cadeia } \\
\text { de valor, minimizando/eliminando tudo } \\
\text { que não agrega valor. Garantir que } \\
\text { os processos são apropriados para } \\
\text { atender os requisitos de projeto. }\end{array}$} \\
\hline & & 10.2. Eliminar perdas & \\
\hline & \multirow{3}{*}{$\begin{array}{l}\text { 11. Processo de } \\
\text { apoio }\end{array}$} & 11.1. Manutenção & \\
\hline & & 11.2. Materiais & \\
\hline & & 11.3. Administração & \\
\hline & 12. Processo direto & 12.1. Operações de serviço & \\
\hline \multirow{3}{*}{$\begin{array}{l}\text { Produção } \\
\text { puxada }\end{array}$} & \multirow{3}{*}{$\begin{array}{l}\text { 13. Produção do } \\
\text { serviço }\end{array}$} & 13.1. Capacidade de produção & \multirow{3}{*}{$\begin{array}{l}\text { Garantir um fluxo de serviços } \\
\text { compatível com a demanda. }\end{array}$} \\
\hline & & 13.2. Balanceamento e fluxo & \\
\hline & & 13.3. Programação da produção & \\
\hline \multirow[b]{2}{*}{ Pessoas } & \multirow{2}{*}{$\begin{array}{l}\text { 14. Gestão de } \\
\text { pessoas }\end{array}$} & 14.1. Capacitação & \multirow{2}{*}{$\begin{array}{l}\text { Capacidade de capacitar e motivar } \\
\text { pessoas para assegurar condições de } \\
\text { implementar melhorias. }\end{array}$} \\
\hline & & 14.2. Motivação & \\
\hline \multirow{3}{*}{$\begin{array}{l}\text { Mensuração/ } \\
\text { Análise das } \\
\text { informações }\end{array}$} & \multirow{2}{*}{ 15. Mensuração } & 15.1. Sistema de informações & \multirow{3}{*}{$\begin{array}{l}\text { Capacidade de selecionar, obter, usar e } \\
\text { melhorar as informações necessárias } \\
\text { para apoiar os processos, estratégia e } \\
\text { melhoria do desempenho. }\end{array}$} \\
\hline & & 15.2. Mensuração do desempenho & \\
\hline & 16. Análise & 16.1. Análise das informações & \\
\hline \multirow[t]{2}{*}{ Resultados } & \multirow[t]{2}{*}{ 17. Resultados } & $\begin{array}{l}\text { 17.1. Resultados operacionais/ } \\
\text { estratégicos }\end{array}$ & $\begin{array}{l}\text { Capacidade de apresentar resultados, } \\
\text { tendências, comparar-se com }\end{array}$ \\
\hline & & 17.2. Resultados comparativos & \\
\hline & thonis & 18.1. Melhorias contínuas & Capacidade de estabelecer ações de \\
\hline IV & einorlas & 18.2. Melhorias radicais & melhoria de forma sistêmica. \\
\hline
\end{tabular}


parcialmente na eliminação das perdas. As empresas "A" e "B" citaram que a prioridade da eliminação das perdas não é maior devido à metodologia utilizada para o cálculo de tarifa, com base nos custos declarados pelas empresas, que permite repasse de custos.

No que se refere aos processos diretos (operações de transporte propriamente ditas), as empresas consideram que todos os parâmetros são muito importantes ou extremamente importantes. Todas as empresas trabalham com ônibus "reserva", mas a empresa "B" salientou que poderia haver um estudo mais detalhado para definir a proporção ótima de veículos necessários, sem comprometer o serviço (acredita que haja superestimativa).

Nas questões referentes à manutenção, todas as empresas consideram todos os parâmetros muito importantes ou extremamente importantes, exceto o que se refere ao compartilhamento de recursos e instalações entre empresas de mesmo consórcio. Sellitto, Borchardt e Araújo (2002) apontam metodologias específicas que as empresas poderiam usar em suas práticas de manutenção: cálculo de vida útil de componentes, modelos de confiabilidade e FMEA e FTA.

Para a base de análise "Produção Puxada", as três organizações consideram todos os aspectos extremamente importantes. Os entrevistados relataram, quanto à aplicação, que possivelmente exista uma capacidade instalada suficiente ou até maior do que a demanda atual e sugerem um estudo sobre a demanda real e o tamanho de frota ideal para a demanda. A demanda real e suas variações ao longo do dia, mês e ano poderiam ser mais bem mapeadas, a fim de se estabelecer um requisito de capacidade para cada empresa.

As três organizações consideram muito importantes ou extremamente importantes os parâmetros relacionados à base de análise "Pessoas". A aplicação vem ocorrendo de modo sistêmico e as empresas têm práticas como grupos de CCQ (Círculos de Controle da Qualidade), reconhecimento de esforços adicionais ou em grupo, precisando, as empresas "A" e "C", consolidar ainda mais essa aplicação.

Com relação aos resultados obtidos na base de análise "Mensuração e Análise das Informações", os parâmetros relacionados aos sistemas de informações, à mensuração do desempenho e à análise das informações foram considera- dos muito importantes ou extremamente importantes pelos entrevistados das três organizações. As empresas " $B$ " e " $C$ " precisam aprimorar o sistema de informações de modo a garantir a interação dos dados provenientes de todas as áreas e processos. As organizações efetuam análise de desempenho dos processos e da organização, estabelecendo planos de ação quando necessário.

Para a base de análise "Resultados", as questões referentes aos Resultados Operacionais e Estratégicos e Resultados Comparativos foram consideradas muito importantes ou extremamente importantes pelas três organizações. A empresa "A" precisa sistematizar a análise de seus resultados, principalmente no que se refere aos indicadores relativos aos clientes; esse problema decorre da dificuldade de conhecer plenamente os clientes e suas necessidades. As empresas "B" e "C" buscam suprir essa dificuldade com pesquisas próprias.

Em relação à base de análise "Ações de Melhoria", as três organizações consideram muito importante ou extremamente importante a implementação sistêmica de ações de melhoria. A empresa "A" já deu mais ênfase, anteriormente, à utilização sistêmica de ferramentas da qualidade. As empresas " $\mathrm{B}$ " e " $\mathrm{C}$ " vêm aplicando e estimulando o uso destas ferramentas, de modo coordenado e estruturado. Com relação às "Melhorias Radicais", as empresas " $A$ " e "B" consideram extremamente importante a empresa ter condições administrativas, de liderança e físicas para efetivar tais mudanças, embora a empresa "A" não se considere preparada para tal. A empresa "C" não considera essa possibilidade frente à situação do transporte e ao histórico da empresa.

\section{DISCUSSÃO DOS RESULTADOS}

O Quadro 4 apresenta a classificação das bases de análise (conforme grau de importância médio, em ordem decrescente) para cada uma das empresas da amostra. Nos casos em que há mais de uma base de análise por empresa, com o mesmo grau de importância médio, a classificação em ordem decrescente considerará a maior média do grau de importância das bases de análise das três empresas.

Quadro 3: Relação entre atributos e valores numéricos do grau de importância e do grau de aplicação.

\begin{tabular}{|l|l|}
\hline \multicolumn{1}{|c|}{ ESGALA PARA GRAUS DE IMPORTÂNCIA } & \multicolumn{1}{c|}{ ESGALA PARA GRAUS DE APLIGAÇÃO } \\
\hline 1. Parâmetro é completamente irrelevante & 1. Não aplica ou aplica de modo inadequado \\
\hline 2. Parâmetro tem pouca importância & 2. Já implementou em áreas isoladas mas não deu continuidade \\
\hline 3. Parâmetro tem importância média & 3. Implementa, porém não de forma sistêmica \\
\hline 4. Parâmetro é muito importante & 4. Implementa em toda organização, mas precisa consolidar \\
\hline 5. Parâmetro é extremamente importante & 5. Implementa de forma sistêmica e consolidada \\
\hline
\end{tabular}


Os dados obtidos sugerem que as prioridades definidas pelas organizações estão vinculadas à estratégia adotada. Neste trabalho, as empresas B e C tomam como referência o Sistema de Gestão baseado no Prêmio Nacional da Qualidade ou no Prêmio ANTP de Qualidade e, até a realização da pesquisa, não haviam considerado a possibilidade de adotar um Sistema de Gestão baseado nos princípios da Mentalidade Enxuta ou do Lean Management ou outra abordagem convergente com os princípios de um sistema enxuto, cuja prioridade seja a otimização dos processos com base no valor especificado pelo cliente.

A Tabela 1 apresenta os graus de importância e de aplicação médios de cada base de análise, obtidos a partir da média das notas atribuídas para cada uma das questões que compõem a base de análise. Cada um dos comentários e justificativas já apresentados no decorrer do trabalho é ponto essencial para compreensão das lacunas e, na medida do possível, descreve o comportamento quanto à amplitude entre as respostas.

Sintetizam-se em gráficos tipo radar (Figura 2, Figura 3 e Figura 4) os valores numéricos atribuídos pelas empresas para cada base de análise, para grau de importância e grau de aplicação. Identifica-se o potencial de melhorias em relação ao que as empresas consideram relevante em cada uma das bases de análise avaliadas e ao que elas efetivamente fazem.

A empresa "A" apresenta a maior defasagem entre o que acredita ser importante para um sistema enxuto e o que efetivamente aplica. O elemento "Valor" apresenta a maior lacuna.

A empresa "B" busca suprir, pelo verificado nas visitas e entrevistas, as lacunas que percebe em relação ao que necessita e ao que tem. Mesmo para aspectos cuja responsabilidade é atribuída ao órgão gestor ou aos consórcios, se a empresa julga que estes não são plenamente atendidos, procura suprir estas deficiências. Com relação às bases de análise "Estratégia", "Valor" e "Resultados", os graus de aplicação atribuídos são maiores que os graus de importância. A organização efetiva ações que, segundo o entrevistado, excedem o necessário no momento atual, mas preparam a organização para situações futuras.

A empresa "C" tem uma postura similar à empresa "B", no sentido de buscar suprir as lacunas implementando ações julgadas necessárias. A empresa "C" vem atuando fortemente nos parâmetros relativos à responsabilidade social e cidadania, por opção da alta administração, e vem procurando atender os critérios de excelência do PGQP ou ANTP. Reconhece que sua estratégia não está focada diretamente na eliminação de desperdícios.

Nas três empresas, a base de análise "Produção puxada" é a que apresenta menor defasagem entre os graus de importância e de aplicação. Na percepção dos entrevistados existe sobra de capacidade instalada frente à atual demanda. Isso caracteriza, segundo os pressupostos de sistema enxuto, uma perda, que poderia ser reduzida por ações de aumento de demanda.

Salienta-se que as organizações estudadas e a ATP-POA (Associação dos Transportadores de Passageiros de Porto Alegre) declararam estar cientes da necessidade de reverter o quadro de perda de passageiros e de propor um serviço apropriado às necessidades da sociedade, sob o risco de terem problemas de sustentabilidade futura. Isso não indica necessariamente agregar custo, mas agregar valor ao serviço, através de novos serviços ou serviços suplementares. No entanto, segundo os entrevistados, não há unanimidade quanto a como chegar a uma situação de sustentabilidade assegurada.

Os entrevistados das empresas " $\mathrm{B}$ " e " $\mathrm{C}$ " declararam que

Quadro 4: Bases de Análise ordenadas pelo grau de importância médio.

\begin{tabular}{|c|c|c|c|}
\hline ORDEM & EMPRESA "A" & EMPRESA "B" & EMPRESA "C" \\
\hline $1 \circ$ & Produção puxada & Produção puxada & Valor \\
\hline $2 \circ$ & Pessoas & Pessoas & Estratégia \\
\hline $3 \circ$ & Mensuração/análise & Ações melhoria & Mensuração/análise \\
\hline $4 \circ$ & Resultados & Mensuração/análise & Pessoas \\
\hline $5 \circ$ & Estratégia & Resultados & Produttados \\
\hline 6o & Sistema de valor & Fluxo de valor & Fluxo de valor \\
\hline $7 \circ$ & Ações melhoria & Sistema de valor & Sistema de valor \\
\hline $8 \circ$ & Fluxo de valor & Produto & Ações melhoria \\
\hline 9o & Valor & Valor & Estratégia \\
\hline $10 \circ$ & Produto & &
\end{tabular}


a estratégia destas organizações está voltada à excelência, ou seja, as organizações buscam oferecer aos usuários do transporte coletivo um serviço diferenciado em termos de organização, limpeza, atendimento, qualidade do veículo dentro da tarifa preestabelecida pelo órgão gestor. Os gestores acreditam que com a diferenciação do serviço, pelo preço estabelecido, poderão minimizar ou reverter o quadro de perda de passageiros. Declararam também, que neste contexto, torna-se essencial a redução dos custos a fim de garantirem a sustentabilidade da organização. O entrevistado da empresa "A" declarou que a empresa tem como estratégia, em relação ao serviço prestado, atender ao padrão mínimo de serviço exigido e monitorado pelo órgão gestor. Acredita que a tendência de queda no número de passageiros não será revertida, pois é conjuntural e conseqüência de políticas nacionais. Neste sentido, para o entrevistado, melhorar

Tabela 1: Graus de importância e de aplicação médios de cada base de análise.

\begin{tabular}{|c|c|c|c|c|c|c|}
\hline \multirow{2}{*}{ BASE DE ANÁLISE } & \multicolumn{2}{|c|}{ EMPRESA "A" } & \multicolumn{3}{c|}{ EMPRESA "B" } & \multicolumn{2}{c|}{ EMPRESA "C" } \\
\cline { 2 - 8 } & IMPORTÂNcIA & APLICAÇÃo & IMPORTANCIA & APLICAÇÃo & IMPORTÂNCIA & APLIGAÇÃo \\
\hline Estratégia & 5,00 & 4,25 & 4,31 & 4,50 & 4,69 & 4,19 \\
\hline Valor & 4,71 & 2,57 & 4,43 & 4,50 & 4,71 & 4,29 \\
\hline Sistema de valor & 5,00 & 4,25 & 4,50 & 4,00 & 4,17 & 3,00 \\
\hline Produto & 4,29 & 3,14 & 4,50 & 4,14 & 4,50 & 4,14 \\
\hline Fluxo de valor & 4,85 & 4,11 & 4,56 & 4,26 & 4,42 & 3,58 \\
\hline Produção puxada & 5,00 & 5,00 & 5,00 & 5,00 & 4,86 & 4,43 \\
\hline Pessoas & 5,00 & 4,50 & 5,00 & 5,00 & 4,50 & 4,00 \\
\hline Mensuração/análise & 5,00 & 5,00 & 4,89 & 4,67 & 4,67 & 4,33 \\
\hline Resultados & 5,00 & 3,90 & 4,80 & 4,90 & 4,50 & 4,20 \\
\hline Ações de melhoria & 4,89 & 3,22 & 5,00 & 4,78 & 3,67 & 3,33 \\
\hline
\end{tabular}

Figura 2: Graus de importância e de aplicação - Empresa "A".

\section{Graus de importância e de aplicação - Empresa "A"}

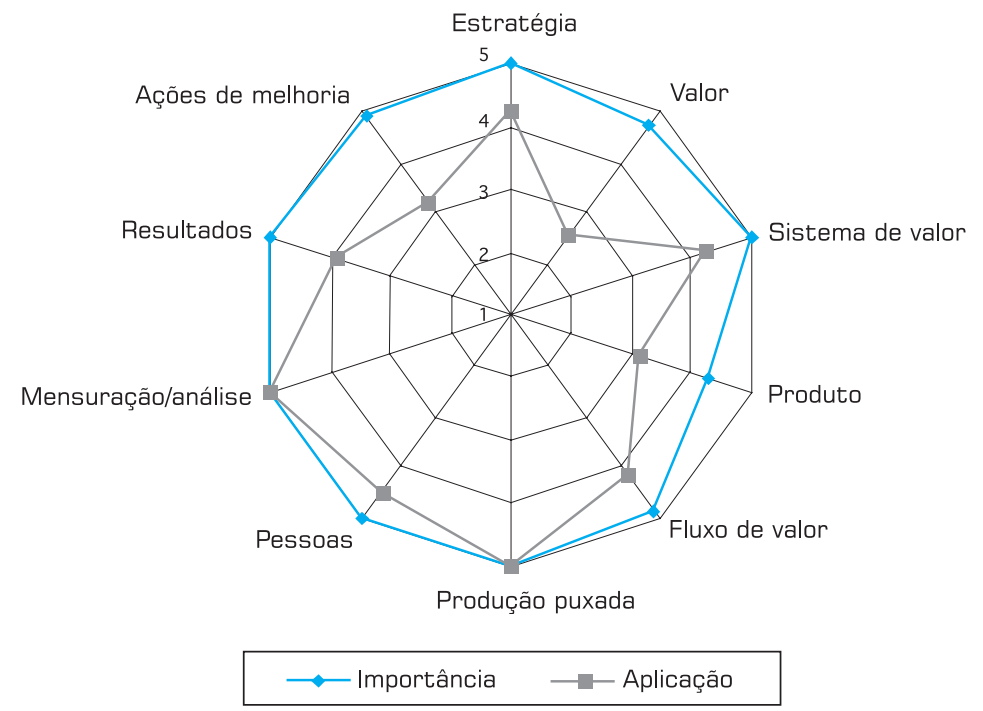


o nível de serviço pode significar aumento de custos sem perspectiva de retorno.

Por outro lado, o cálculo da tarifa toma como referência os custos declarados das empresas. Entrevistados de duas organizações mencionaram que o cálculo da remuneração pode ser um fator limitante para a busca de melhorias nos processos e pode gerar um paradoxo em relação à melhoria do sistema como um todo. Alternativas podem ser propostas,

Figura 3: Graus de importância e de aplicação - Empresa "B".

\section{Graus de importância e de aplicação - Empresa "B"}

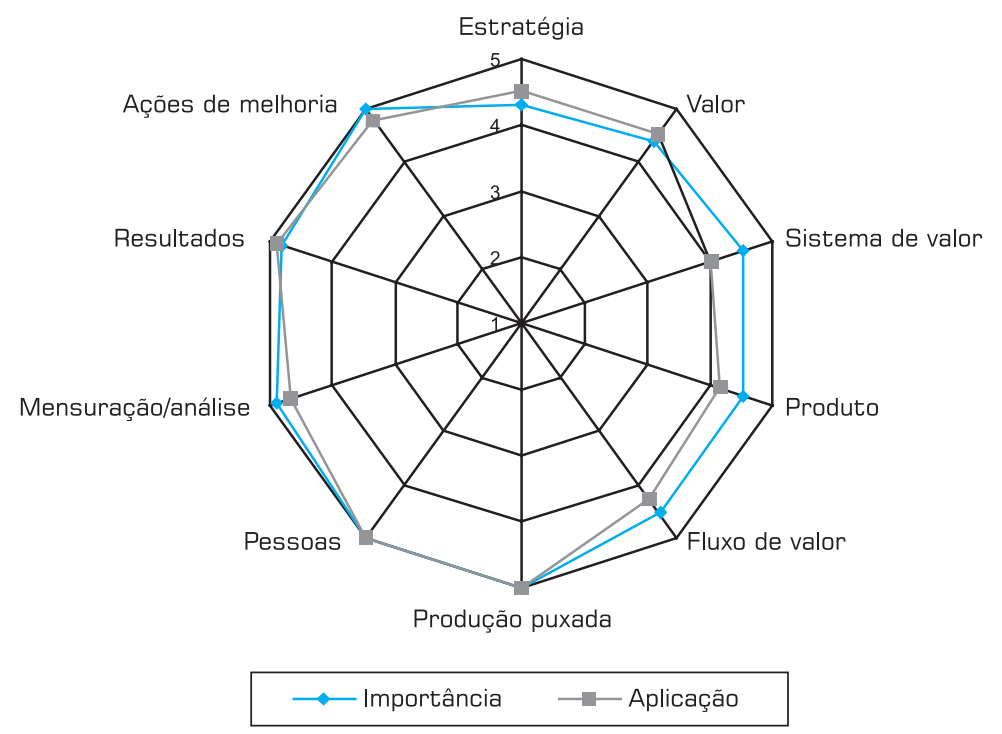

Figura 4: Graus de importância e de aplicação - Empresa "C".

Graus de importância e de aplicação - Empresa "C"

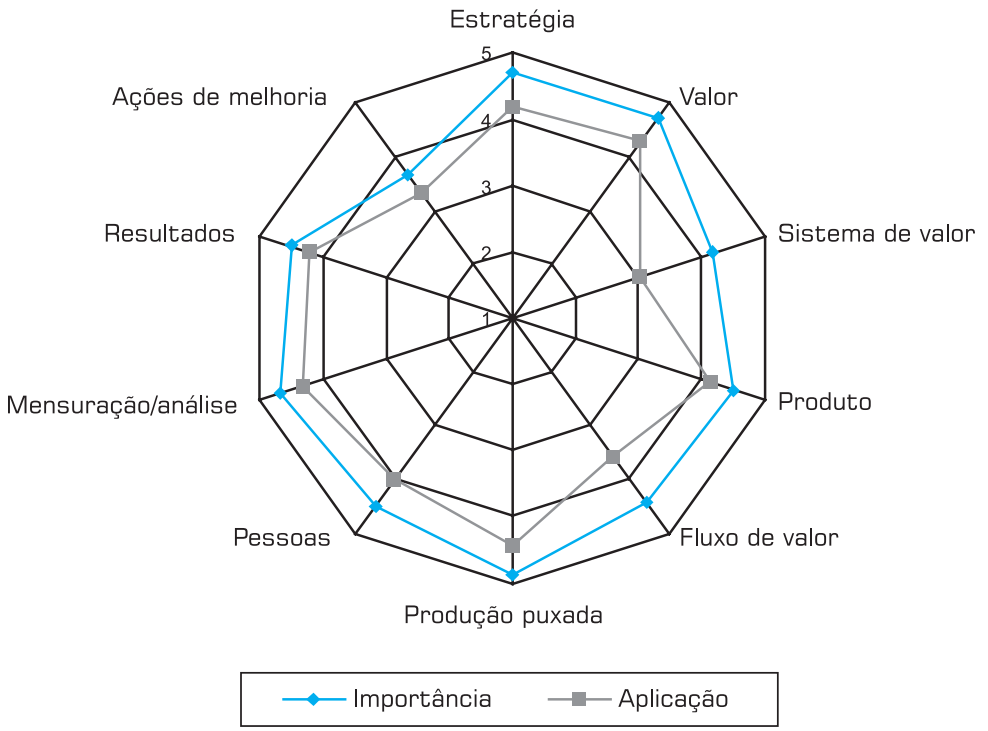


não considerando apenas custos, mas que também incluam o aumento potencial de demanda no cálculo. Exemplificando o contra-senso, um dos entrevistados declarou que pode ser vantajoso que uma organização mantenha uma frota maior do que a necessária, já que isso implica em aumento do patrimônio da empresa e o cálculo da remuneração do serviço de transporte a ser pago para a empresa parte da base de custos das mesmas.

Apresentam-se a seguir as considerações finais e propostas de continuidade da pesquisa.

\section{CONSIDERAC̣ÕES FINAIS E CONTINUIDADE DE PESQUISA}

A partir do referencial teórico estabelecido, foi possível elaborar um instrumento de avaliação específico para as empresas de transporte coletivo rodoviário de Porto Alegre, considerando termos teóricos e princípios convergentes para a busca da melhoria dos processos. Desta forma, o objetivo proposto para essa pesquisa foi alcançado. As lacunas entre o grau de importância e de aplicação dos parâmetros avaliados indicaram os pontos de maior defasagem entre parâmetros relevantes para as empresas estudadas e estão disponíveis para as empresas, o que pode motivar eventuais reformulações de estratégias.

Destaca-se a fragilidade no conhecimento do cliente e de suas necessidades por parte de uma das empresas; esse ponto é que deve direcionar a proposição de valor da em- presa e guiar ações específicas para agregar valor ao serviço oferecido. O sistema de valor também apresentou defasagem importante, indicando a necessidade de ações conjuntas em toda a cadeia de valor. Como as empresas estudadas pertencem ao grupo de empresas cujos gestores conhecem os conceitos relativos aos sistemas enxuto e da qualidade, os resultados sugerem que o potencial de melhoria dos processos das organizações dos demais grupos pode ser ainda mais significativo.

Como continuidade de pesquisa, sugere-se mapear todas as empresas da região, identificando o perfil geral do setor. Desta forma, será possível propor ações específicas e diretrizes válidas para o segmento e região. Um mapeamento das práticas e ferramentas que contribuem para a eliminação de perdas e otimização do uso de recursos, já utilizadas pelas empresas, poderá ser efetuado. Deste modo, pode-se compilar essas informações e sugerir um conjunto de técnicas, práticas e ferramentas capazes de contribuir para tornar mais enxutas as empresas de transporte coletivo urbano.

Um estudo sobre o compartilhamento de recursos das empresas de mesmo consórcio é sugerido, eis que foram identificados indícios de que pode ser vantajosa para as organizações da mesma bacia geográfica a divisão de veículos reserva, instalações, recursos de manutenção, estoques de peças de reposição, etc. Também se sugerem mais pesquisas sobre a forma de organização dos consórcios, procurando identificar os fundamentos desta associação e enquadrá-los nas teorias existentes sobre cooperação.

\title{
Artigo recebido em 21/12/2005 Aprovado para publicação em 29/05/2007
}

\author{
- Referências \\ ANTUNES, Jr. J. Em direção a uma teoria \\ geral do processo na administração da \\ produção: uma discussão sobre a pos- \\ sibilidade de unificação da Teoria das \\ Restrições e da teoria que sustenta a \\ construção dos sistemas de produção \\ com estoque zero. Tese (Doutorado em \\ Administração de Empresas) - PPGA, \\ UFRGS, Porto Alegre, 1998. \\ ASSOCIAÇÃO NACIONAL DE \\ TRANSPORTES PÚBLICOS (ANTP). Prêmio \\ ANTP de Qualidade 2005. São Paulo : ANTP \\ 2004. Disponível em: <http://www.antp. \\ org.br >. Acesso em: 02 jun. 2004. \\ ASSOCIAÇÃO NACIONAL DE \\ TRANSPORTES PÚBLICOS (ANTP). \\ Transporte Humano - cidades com qualidade \\ de vida. São Paulo : ANTP, 1999. \\ AZAMBUJA, A. M. W. Análise de eficiência \\ na gestão do transporte urbano por ônibus \\ em municípios brasileiros. Tese (Doutorado \\ em Engenharia de Produção) - PPGEP, \\ UFSC, Florianópolis, 2002. \\ BALLARD, G. Key differences between lean \\ construction and current forms of project \\ management. Disponível em: < http:// \\ www.leanconstruction.org $>$. Acesso em \\ 16 nov. 2003. \\ BNQP: Baldrige National Quality \\ Program. Criteria for performance excelen- \\ ce. Disponível em: http://www.quality. \\ nist.gov/Business_Criteria.htm. Acesso \\ em: 01 nov. 2005. \\ BORCHARDT, M. Diretrizes para a imple- \\ mentação dos princípios da Mentalidade \\ Enxuta: o caso das empresas de trans- \\ porte coletivo rodoviário urbano. Tese \\ (Doutorado em Engenharia de Produção)- \\ PPGEP, UFSC, Florianópolis, 2005. \\ CERRA, A.; BONADIO, P. As relações entre \\ estratégia de produção, TQM e JIT - \\ estudos de caso em uma empresa do \\ setor automobilístico e em dois de seus \\ fornecedores. Gestão e Produção, v. 7 , \\ n. 3, p. 305-320, 2000. \\ COSTA, M. et al. Estudo comparativo \\ entre empresas de ônibus utilizando \\ AHP: o caso das empresas consorciadas \\ de Porto Alegre. In: NASSI, C. et al. (Org.). \\ Transportes: experiências em rede. Rio de \\ Janeiro: FINEP, 2001.
}

CUNNINGHAM, L.; YOUNG, C.; LEE, M. Methodological triangulation in measuring public transportation service quality. Transportation Journal, v. 40 n. 1 , p. 35-48, 2000.

CYPRIANI, I.; GUEDES C. A importância dos sistemas de informação sobre usuários na qualidade do serviço de transporte coletivo urbano. Revista dos Transportes Públicos/ANTP, v. 25, n. 97, p. 63-78, 2002.

DAVIS, M. Fundamentos da Administração da Produção. Porto Alegre: Bookman, 2001.

EPTC. Empresa Pública de Transporte e Circulação de Porto Alegre - RS. Disponível em <http://www.eptc.com.br>. Acesso em: 02 jun. 2004. 


\section{- Referências}

FULLERTON, R.; MCWATTERS, C.; FAWSON, C. An examination of the relationship between JIT and financial performance. Journal of Operations Management, n. 21, p. 383-404, 2003.

HENDERSON, B.; LARCO, J. Lean Transformation: how to change your business into a lean enterprise. Richmond: The Oaklea Press, 2002.

HINES, P.; TAYLOR, D. Enxugando a empresa: um guia para implementação. São Paulo: IMAM, 2000

JACKSON, T.; JONES, K. Implementing a lean management system. Portland: Productivity Press, 1996.

JOHNSTON, R. et al. Target setting for evolutionary and revolutionary process change. International Journal of Operations \& Production Management, v. 21, n. 11, p. 1387-1403, 2001

KAYNAK, $\mathrm{H}$. The relationship between total quality management practices and their effects on firm performance. Journal of Operations Management, n. 21 , p. 405-435, 2003.

NILSSON, L.; JOHNSON, M.; GUSTAFSSON, A. The impact of quality practices on customer satisfaction and business results: product versus service organizations Journal of Quality Management, v. 6, n. 4 p. 5-27, 2001

NTU - ASSOCIACÃO NACIONAL DAS EMPRESAS DE TRANSPORTES URBANOS Desoneração dos custos e barateamento das tarifas do transporte público. Setembro, 2004. Disponível em: < http://www.ntu. org.br/frame_publicacoes.htm>. Acesso em: 27 set. 2004

PORTER, M. Vantagem competitiva: criando e sustentando um desempenho superior. Rio de Janeiro: Campus, 1999.

ROTHER, M.; SHOOK, J. Aprendendo a enxergar: mapeando o fluxo de valor para agregar valor e eliminar o desperdício. São Paulo: Lean Institute Brasil, 1999.
SÁNCHEZ, A.; PÉREZ, M. Lean indicators and manufacturing strategies. International Journal of Operations \& Production Management, v. 21, n. 11, p. 1433-1451, 2001.

SCHONBERGER, R. Building a chain of customer. New York: The Free Press, 1990.

SELLiTTO, M. Medição e controle de desempenho estratégico em sistemas de manufatura. Tese (Doutorado em Engenharia de Produção) - PPGEP, UFRGS, Porto Alegre, 2005.

SELLITTO, M.; BORCHARDT, M. Medição e controle do relacionamento de usuários com o objeto de serviço na indústria de transporte coletivo de passageiros. Anais do XXIV ENEGEP, Florianópolis, 2004.

SELLITTO, M.; BORCHARDT, M.; ARAÚJO, D. Manutenção centrada em confiabilidade: aplicando uma abordagem quantitativa. Anais do XXII ENEGEP. Curitiba: ABEPRO, 2002.
Assessing the degree pomptness of a service industry to adopt lean thinking. Revista Eletrônica de Administração, v. 9, n. 6, p. 105-130, 2003.

SELLITTO, M., BORCHARDT, M.; PEREIRA G. Avaliação multicriterial de desempenho: um estudo de caso na indústria de transporte coletivo de passageiros. Gestão \& Produção, v. 13, n. 2 , p. $339-352,2006$.

STS. Sistema Transportador Sul. Disponíve em: < http://www.sts.com.br>. Acesso em: 02 jun. 2004

VOSS, C.; TSIKRIKTSIS, N.; FROHLICH, $\mathrm{M}$. Case research in operations management. International Journal of Operations \& Production Management, v. 22, n. 2 p. $195-219,2002$

WOMACK, J.; JONES, D. A Mentalidade enxuta nas empresas: elimine o desperdício e crie riquezas. Rio de Janeiro: Campus, 1998.

YIN, R. Estudo de caso: planejamento e método. Porto Alegre: Bookman, 2001.

\section{- Agradecimentos}

Os autores agradecem à UNISINOS pelo financiamento de pesquisa, à Profa. Dra. Ana Maria Volkmer Azambuja (FURG), ao sr. Jorge Roni Martins (consultor na área de transportes coletivos) e ao bacharel Gustavo Simionovisky (ATP - POA) pelas contribuições durante a elaboração do instrumento de diagnóstico. Igualmente agradecem às três empresas participantes pela atenção e disponibilização de informações.

\section{- Sobre os autores}

\section{Miriam Borchardt}

UNISINOS - Universidade do Vale do Rio dos Sinos

Professora e pesquisadora

End.: Av. Unisinos, 950 - CEP 93200-000 - São Leopoldo - RS

Tel.: (51) 3591-1100 ramal $1551 /$ (51) 3590-8172

E-mail: miriamb@unisinos.br

\section{Miguel Afonso Sellitto}

UNISINOS - Universidade do Vale do Rio dos Sinos

Professor e pesquisador

End.: Av. Unisinos, 950 - CEP 93200-000 - São Leopoldo - RS

Tel.: (51) 3591-1100 ramal 1577 / (51) 3590-8172

E-mail: sellitto@unisinos.br

\section{Giancarlo Medeiros Pereira}

UNISINOS - Universidade do Vale do Rio dos Sinos

Professor e pesquisador; coordenador do PPGEP

End.: Av. Unisinos, 950 - CEP 93200-000 - São Leopoldo - RS

Tel.: (51) 3591-1100 ramal 1566 / (51) 3590-8172

E-mail: gian@unisinos.br 